INSIGHT

\title{
An evaluation of clinical dietetic student placement case-mix exposure, service delivery and supervisory burden
}

\author{
Roger HUGHES' and Ben DESBROW ${ }^{2}$ \\ 'School of Health and Sport Sciences, University of the Sunshine Coast, Maroochydore, and '2School of Public \\ Health and Research Centre for Clinical and Community Practice Innovation, Griffith University, Gold Coast, \\ Queensland, Australia
}

\begin{abstract}
Aim: To evaluate the attributes of clinical dietetics student placement exposure to patient case-mix and supervision, types of services delivered and to estimate and compare costs and benefits of student activity and supervision while on placement.

Methods: Descriptive study of three annual cohorts of student dietitians $(n=59)$ collecting data prospectively over a continuous 10-week clinical placement period. Data focused on student case-mix exposures and student and supervisor verified time utilisation. Descriptive analysis of data relating to student case-mix exposure, student service delivery and direct supervisory practices was performed to explore the attributes of student placement experiences. Student and supervisor time utilisation data were used to model estimates of dollar costs and benefits based on occasion of service as a measure of clinical productivity.

Results: Data collected indicate that student service delivery activity increases and direct supervision decreases significantly as time on placement increases. The minimum occasion of service exposure required to achieve supervisor assessment of entry-level competency was 47 occasion of service (mean 165.8 occasion of service) and the maximum 306 occasion of service. Over one-third of all occasion of service provided by students was not directly supervised. Cost-benefit estimates indicate that a student needs to be over $80 \%$ as time efficient throughout the placement as a new graduate to offset the costs of direct student supervision.

Conclusion: These data highlight the variability of student clinical placement experiences and exposure to learning
\end{abstract} opportunities and support evidence-based dialogue about resource exchange to support student placements.

Key words: clinical dietetics, competency, evaluation, supervision.

\section{Introduction}

Workforce preparation for the dietetics profession in Australia has for many years been based on a mix of university and practice-based tuition and supervision. Practice-based internships (also referred to as professional placements) are recognised as an important process for entry-level competency development because it enables students to apply knowledge and skills to real problems in real-world settings. ${ }^{1,2}$ Experiential learning has previously been identified

R. Hughes, PhD, APD, Professor and Discipline Leader of Nutrition and Dietetics

B. Desbrow, PhD, APD, Convenor Bachelor of Nutrition and Dietetics Program

Correspondence: R. Hughes, School of Health and Sport Sciences,

University of the Sunshine Coast, Maroochydore, Qld 4558, Australia.

1 Email: rhughes1@usc.edu.au

Accepted July 2010 as a critical process in competency development by nutrition and dietetic practitioners in the Australian workforce, ${ }^{3,4}$ University program accreditation by the Dietitians Association of Australia is contingent on the provision of at least 10 weeks of student placement in clinical dietetics practice. This stipulation assumes that this period of time enables students to receive adequate exposure to a variety and quantity of clinical cases and associated practitioner supervision to enable the development and consolidation of clinical and professional competencies. To date there has been limited attempts to quantify and describe the nature of student case-mix and supervisory exposures among clinical dietetic students, and as a result, the assumptions that underpin the 10-week placement period are difficult to verify. This lack of evidence stifles the development and evaluation of innovative supervisory and placement models.

Over the last decade there have been significant changes in the dietetic workforce preparation environment in part 
responsive to workforce development trends ${ }^{5}$ and changes in the health sector. ${ }^{6}$ Growth in the number of university programs in nutrition and dietetics, increased student enrolments and the associated growth in demand for supervision by universities has increased the importance of a focus on this aspect of dietetic workforce preparation, and has led to a range of initiatives designed to increase supervisory capacity. ${ }^{7}$ It has also prompted the development and evaluation of new models of clinical education with an emphasis on optimising supervisory capacity and sustainability. ${ }^{8,9}$

Recent changes in some state-based enterprise bargaining agreements (such as in Queensland Health) that codify the facilitation of student internships as a core duty of public sector dietetic work, have reinforced the need for an active partnership between the university sector and the profession (practitioners and departments engaged in supervision). As with most ongoing partnerships, the student internship partnership between educational institutions and the profession involves an exchange of, as yet, largely unmeasured costs and benefits. These costs and benefits are both tangible and intangible. Tangible costs may include the opportunity cost of supervisor time away from service delivery and intangible costs include increased stress on supervisors. Tangible benefits may include increased department productivity associated with student service provision and intangible benefits such as the 'increased energy' previously described by supervisors as a benefit of having students in their departments. ${ }^{7}$

While there is a developing literature on supervision as a component of clinical education in medicine, ${ }^{10}$ nursing ${ }^{11}$ and allied health ${ }^{12}$ fields, there is a limited literature that can be used to inform an evidence-based assessment of the costs and benefits of clinical dietetics internships for supervising practitioners and their organisations. This matches the similarly limited scholarship informing how dietitians develop competencies and what learning opportunities most effectively support competency attainment. This gap in the workforce development scholarship limits informed development of supervisory support strategies and resource exchange between universities and clinical practice placement sites. Evidence from a 2002 Australian survey among dietetic department managers and supervisors indicated that although student dietitian internships imposed a range of stressors on practitioners involved in supervision, there was a net overall benefit that outweighed the costs. ${ }^{7}$ The only published economic evaluation of dietetic internships for hospital dietetics department conducted in the USA in $1994^{13}$ demonstrated a net economic gain associated with increased productivity for departments supervising interns (i.e. the benefits outweighed the costs). Building the evidence base about supervisory attributes and practices, and the resource and other exchange associated with clinical internships, is required in response to the increasing pressures on the profession resulting from developments in the university and health sectors.

The present study aimed to describe the placement experience for students in terms of case-mix exposure, supervision and service contributions and to estimate and compare the costs and benefits of student internships in clinical dietetic departments from an economic perspective.

\section{Methods}

Ethics approval for the present study was obtained from the relevant University Human Research Ethics Committee. Students participated in pre-placement workshops that outlined the data collection protocol, during which informed consent was obtained.

The data collected in the present study represent prospective self-reported data from students in their final placement semester of the Master of Nutrition and Dietetics program at the study university. Students attended consecutive placements ( 5 weeks each) at two locations where supervision was conducted using a one-on-one student to supervisor model. Data were collected over the entire 10-week clinical placement period by all students in three consecutive annual student cohorts (A-C), using a case-mix data collection form developed initially as a placement case-mix monitoring mechanism. This form was modified to include data as described in Table 1. This table also includes the assumptions and questions that these data collected were designed to help describe and test. Student records of supervisor time utilisation relating to supervision of each student's clinical occasions of service (OOS) were verified by supervisors (signed off) to ensure the accuracy of the supervisor time data. OOS were defined as any occasion of student interaction with a clinical case involving some aspect of nutrition and dietetic service delivery (including observation, assessment, education, planning, review and documentation or communication with other health professionals about the case).

Students were instructed prior to placement on the completion of the data collection form, the purpose of the data collected and the mechanism for data submission. Students kept daily records of their activity using these forms and submitted completed forms on a weekly basis by mail or fax. These data forms were collated and entered onto SPSS software (version 17.0, SPSS Inc, Chicago, IL, USA) for analysis, after first being checked by the authors and complexity of case assigned based on case description and service delivered responses by students. In this way, author rather than student categorisation of case complexity was ensured to limit the impact of increasing student confidence on placement effecting categorisation of case complexity. End of placement debriefing meetings were conducted to discuss the data collection protocol and to confirm data recorded.

Descriptive statistics were used to describe the distribution of student placement load by site, the total OOS provided by students on placement, the type and complexity of service mix provided by students and the variability in OOS and direct supervision between students. Chi-squared $\left(\chi^{2}\right)$ analysis was used to compare the distribution of responses to categorical variables including week of placement by case complexity and service type. The Kruskal-Wallis test was used to test for differences in mean student service and 
JOBNAME: No Job Name PAGE: 3 SESS: 23 OUTPUT: Wed Oct 20 19:42:22 2010 SUM: 9AEF557E

/v2503/blackwell/journals/ndi_v67_i4/16ndi_1478

R. Hughes and B. Desbrow

Table 1 Data collection items, assumptions and questions

\begin{tabular}{|c|c|c|}
\hline Data item & Response options & Assumptions/questions \\
\hline Week of placement & $1-10$ & $\begin{array}{l}\text { With increasing time on placement, student } \\
\text { competencies and productivity would increase. } \\
\text { This would be observable in reduced } \\
\text { supervision time needed and increased } \\
\text { frequency of patient services. }\end{array}$ \\
\hline Placement site & $\begin{array}{l}\text { Hospital location of Nutrition and Dietetic } \\
\text { department supervising student }\end{array}$ & $\begin{array}{l}\text { Do different placement sites have different } \\
\text { practices in terms of student supervision and } \\
\text { case-mix exposure? }\end{array}$ \\
\hline $\begin{array}{l}\text { Patient disease } \\
\text { category }\end{array}$ & $\begin{array}{l}\text { Students describe patient type, interpreted by } \\
\text { researchers at data entry and categorised into } \\
11 \text { major disease categories. One of these } \\
\text { categories included multiple diseases to } \\
\text { include patients with obviously more than one } \\
\text { discrete disease. }\end{array}$ & $\begin{array}{l}\text { Reflects student perspective of patient type as } \\
\text { reflected in patient description. Case-mix will } \\
\text { diversify with increasing stage of placement as } \\
\text { supervisors gain confidence in students or } \\
\text { respond to university expectations about } \\
\text { case-mix exposure. }\end{array}$ \\
\hline Complexity of case & $\begin{array}{l}\text { Student rating on a } 3 \text {-point scale of } 1=\text { simple, } \\
2=\text { medium, } 3=\text { complex. }\end{array}$ & $\begin{array}{l}\text { Complexity of case will be associated with } \\
\text { greater student and supervision service times. }\end{array}$ \\
\hline $\begin{array}{l}\text { Type of service } \\
\text { provided }\end{array}$ & $\begin{array}{l}\text { Students report service description, interpreted } \\
\text { by researchers at data entry into seven service } \\
\text { categories. }\end{array}$ & $\begin{array}{l}\text { Observation only is expected in the first weeks of } \\
\text { placement and is likely to taper off as } \\
\text { supervisor feels comfortable with student } \\
\text { competency. }\end{array}$ \\
\hline $\begin{array}{l}\text { Student service } \\
\text { time/case }\end{array}$ & Students report time taken in servicing each case. & $\begin{array}{l}\text { Time of student service and time of supervision } \\
\text { are key data variables for cost and benefit } \\
\text { calculations, can be converted to } \$ \text { values. }\end{array}$ \\
\hline $\begin{array}{l}\text { Supervisors service } \\
\text { time/case }\end{array}$ & $\begin{array}{l}\text { Students report time taken of supervisor for each } \\
\text { case serviced with direct patient care } \\
\text { supervision, student debriefing and reporting. } \\
\text { Verified by supervisor. }\end{array}$ & $\begin{array}{l}\text { Time of supervisor represents the opportunity } \\
\text { cost (forgone opportunity for direct dietitian: } \\
\text { patient services). }\end{array}$ \\
\hline
\end{tabular}

supervisor time spent per OOS across stage of placement, complexity of case and type of service. A P-value of $<0.05$ was used to determine statistical significance for all tests.

Simplified cost-benefit analysis was conducted with the purpose of answering the question is the benefit of the intervention (i.e. student placement) greater or smaller than 3 the costs when both are measured in dollar terms'. ${ }^{14}$ As there was no comparison of different intervention options so the economic analysis represents partial economic evaluation. ${ }^{15}$

In order to calculate the cost of student supervision on placement sites, a number of assumptions were applied, including:

- that the main cost to supervision was the time lost (opportunity cost of supervision that could be used in conducting normal service delivery if not supervising), and

- that supervisors are normally senior practitioners being paid at higher than entry-level rates, which should be factored into cost estimate calculations $(\$ 50 /$ hour used here representing approximate salary costs of a senior practitioner equivalent to top of HP4 scale in Queensland Health).

The assumptions used to calculate benefit estimates for active student OOS (all OOS minus services that only involved observing the supervising dietitian) included:

- The hourly rate for a graduate dietitian being $\$ 25 /$ hour (salary costs based on entry-level HP scale Queensland Health)
- That a student on placement is not necessarily as time efficient in delivering dietetic services as a competent graduate, so an efficiency factor needs to be applied when estimating benefits (i.e. a student may take longer to deliver an equivalent service). Four efficiency factors (40\%, 60\%, 80\% and 100\%) were applied to model three benefit estimates of student OOS.

\section{Results}

A total of 59 students across three student cohorts completed case-mix data forms for 10 weeks each, providing data for a total of 590 weeks of placement distributed over 19 placement sites as summarised in Table 2 .

Across the whole student sample ( $\mathrm{n}=59)$, the mean number of OOS provided over the 10-week placement period was 165.8 OOS (range between cohorts mean 138.3188.3 OOS). This varied considerably between each cohort and mean OOS varied considerable by week of placement, tending to increase with each placement week. Total OOS exposure by students varied considerably at completion of the 10-week placement period (at competency assessment) (Figure 1: min 49-306 max OOS over 10 weeks). As all students in this sample graduated after this period, this is a measure of the OOS exposure required to be assessed as competent. Across the three student cohorts, the distribution of primary disease categories of cases serviced by students 
JOBNAME: No Job Name PAGE: 4 SESS: 23 OUTPUT: Wed Oct 20 19:42:22 2010 SUM: 6DCB9E16

Table 2 Descriptive data on student numbers, occasions of service (OOS) and placement sites

\begin{tabular}{lcrr}
\hline & Cohort A & Cohort B & Cohort C \\
\hline Number of students in cohort & 18 & 21 & 20 \\
Number of clinical placement sites & 12 & 19 & 15 \\
- Major tertiary hospital & 6 & 6 & 6 \\
- Provincial/rural hospital & 6 & 13 & 9 \\
Total OOS & 3016 & 3954 & 2766 \\
Mean OOS per student over 10 weeks & 167.5 & 188 & 138.3 \\
Range of total OOS by student over 10 weeks & $69-236$ & $76-306$ & $47-243$ \\
\hline
\end{tabular}

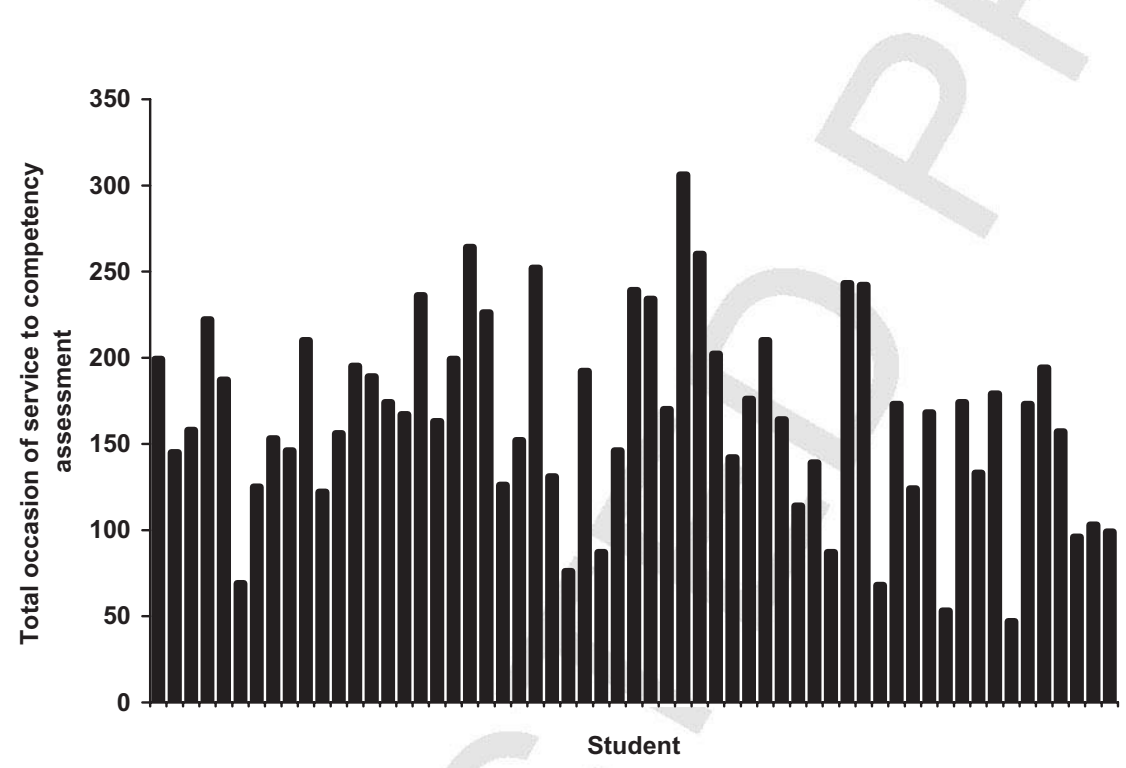

Figure 1 Number of occasions of service required to achieve competency (end of placement)—whole sample.

(including observation only) was spread across over 11 categories, with geriatric related care (20\%), cancer (15\%), diabetes (10\%) and multi-disease cases (15\%) the most prominent. Paediatric and psychiatric disease cases were the only primary disease categories (of 11) making up less than $5 \%$ of OOS across the student sample. There was a significantly different case-mix exposure for disease category by total OOS (case exposure categories $<100 ; 100-200,>200$ : $\left.\chi^{2}=73.5, P<0.001\right)$. Students who were exposed to higher total OOS (>200/10-week placement) were twice as likely to have serviced obesity and cardiovascular disease related cases than students with both lower total case exposure categories. Students with low case exposure ( $<100$ cases) were more likely to have limited to no case exposure to psychiatric and paediatric cases than students with higher total case exposures $\left(\chi^{2}=18.5, P=0.046\right)$.

Passive OOS (observation only) was limited to $7.5 \%$ of all student service episodes. In all three cohorts, there was a significant reduction in the proportion of passive OOS episodes ('observation only') with increasing placement week, corresponding with significant increases in active service delivery (including assessment, patient education, nutrition support planning, documentation/communication and multiple services: $\left.\chi^{2}, P<0.001\right)$. Approximately one-quarter (24.8\%) of student service activity involved patient follow up and review and over one-third (35.9\%) were multiple services (involving a combination of assessment, education, nutrition support planning, etc.). Single episodes of nutrition care planning and documentation were less common (8.4\% and $2.9 \%$ respectively).

The proportion of case complexity for each OOS varied between cohorts, with the majority of cases serviced by students being classified as simple cases (Cohort A: range $54.5-64.2 \%$ as simple, Cohort B: range $63.5-74.6 \%$ as simple, Cohort C: range $59.1-80.0 \%$ as simple). There was a significant difference in distribution of case complexity by week of placement across all three student cohorts $\left(\chi^{2}\right.$, $P<0.02$ ), but there was no clear trend suggesting increasingly complex case-load with increasing duration on placement. There was also considerable variability between students in each cohort regarding exposure to complex cases.

The mean student time per OOS was similar between cohorts averaging close to 40 minutes (Cohort A: $37.8 \pm$ 26 minutes; Cohort B: $42 \pm 31$ minutes; Cohort C: $36 \pm$ 26 minutes). There was a significant difference in mean time per student OOS by week of placement (Kruskal-Wallis $\chi^{2}$, Cohort A: $\chi^{2}=25.9, P=0.002$, Cohort B: $\chi^{2}=59.6, P=$ 0.001 and Cohort $C: \chi^{2}=49.2, P=0.001$ ), with length of OOS reducing with time on placement. 


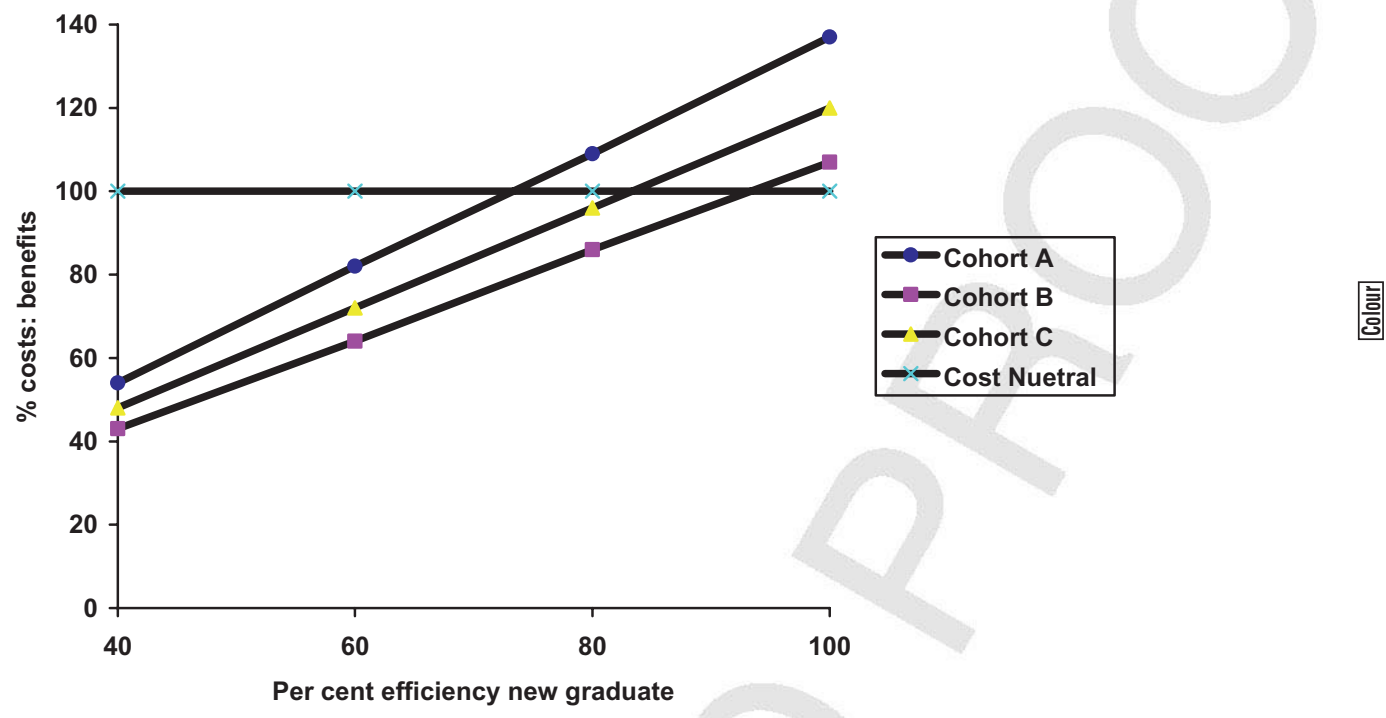

Figure 2 Cost-benefit estimates of student placement using 40\%,60\%, 80\% and 100\% entry-level efficiency models.

There was a significantly larger mean time for complex cases versus simple across the three student cohorts (Cohort A: simple 31.8 minutes vs complex 43.6 minutes per OOS; Kruskal-Wallis, $\chi^{2}=199, P<0.001$, Cohort B: simple 37.8 minutes vs complex 48.9 minutes per OOS; KruskalWallis, $\chi^{2}=143, P<0.001$, Cohort C: simple 34 minutes vs complex 42.9 minutes per OOS; Kruskal-Wallis, $\chi^{2}=103$, $P<0.001)$.

The total time estimate for the whole student cohort in direct service delivery (other than observation) averaged 10.2 hours per placement week, with considerable variability between cohorts $(\mathrm{A}=10.1$ hours/week, $\mathrm{B}=12.7$ hours/ week, $C=7.7$ hours/week). This represents approximately $25 \%$ of the total clinical placement on-site time in direct service delivery.

Estimates of supervisor time utilised to supervise students providing services averaged 4.3 hours/week. There was a significant difference in mean supervisor time per student OOS by week of placement in all three student cohorts (Kruskal-Wallis $\chi^{2}$ : Cohort A, B and C, $P<0.0001$ ) with supervision time reducing with advancing weeks of placement. Supervision time was significantly greater with complex cases in all cohorts (Kruskal-Wallis $\chi^{2}$ : Cohort A, B and $C, P<0.003)$.

There was a significantly different mean supervision time by service category (Kruskal-Wallis $\chi^{2}$ : $P<0.0001$ ), with OOS involving multiple service delivery involving the most supervision time. Student observation of supervisors providing services (passive OOS) indicates the mean length of supervisor service delivery was between 25 and 32 minutes across the three student cohorts.

Approximately one-third (Cohort $\mathrm{A}=33.5 \%$, Cohort B = $32.6 \%$, Cohort $\mathrm{C}=35.8 \%$ ) of all OOS provided by students involved no direct supervision, with most unsupervised OOS occurring in the later placement period.
Figure 2 compares the total cost estimate of student supervision by supervisors (opportunity cost of hours supervisor time@ \$50/hour), with four benefit estimates based on students performing at $40 \%, 60 \%, 80 \%$ and $100 \%$ entrylevel efficiency (using a hourly benefit value of $\$ 25 /$ hour service). The intersection of the cost and benefit estimate lines (the point at which a student needs to be as efficient as a new graduate for the benefits of their time in service delivery to equal the opportunity costs of supervision) varied between cohorts (Cohort A 73\%; Cohort B 93\%, Cohort C $83 \%)$.

\section{Discussion}

The present study is the first known investigation of student dietitian exposure to case-based learning and practice development during clinical placements. It also provides some of the first descriptive evidence about student supervision practices and basic cost and benefit estimates relating to clinical student placements. As a result, there is little available and relevant literature against which to compare these findings. ${ }^{10-12}$

What has been most interesting in the present study is the marked variability in student exposure to patient OOS between placement sites, the small mean number of OOS in many sites and the differences in direct supervision practices. It is recognised that differences in the number of suitable patients able to be seen by students (particularly in the early stages of placement) may exist between sites. Similarly, supervisory styles and capacity vary between placement sites and this influences individual student experiences on placement.

Student exposure to complex cases varied considerably from week to week, and between students, but did not seem to reflect a trend of increasing complexity of cases with 
greater experience in placement. The variability between individual students in simple versus complex case-mix exposure probably reflects the activity of the placement site as much as the practices of supervisors regarding student casemix allocation. These findings reinforce the importance of monitoring student case-mix exposures and competency development opportunities while on placement, so that strategies can be employed to ensure adequate exposures.

The data provided by the present study support the hypothesised effect of placement experience on student service delivery (as time on placement increases, mean weekly OOS increases). Mean supervision times per OOS conversely reduce with increasing placement time. While it is not possible to categorically state that this is the result of competency gain over time resulting in greater productivity and reducing supervision burden, it is a probable explanation. The increasing proportion of indirectly supervised OOS with increasing placement time most likely reflects supervision practices that reflect confidence in student competence after initial assessment and observation periods. Working independently as a practitioner is arguably an important part of the student's competency development experience on placement, particularly towards the final weeks of placement.

Given that all students in these cohorts were assessed by supervisors as competent on completion of their 10-week placement, the variability of OOS exposure prior to assessment of entry-level competence (range 47-306 OOS) raises some important issues. First, how large an exposure to service delivery do students require to develop competencies to the point that they are assessed as competent? The Dietitians Association of Australia program accreditation standards stipulate that at least 10 weeks of clinical placement exposure is required to ensure clinical competency development for entry-level practice. Is it the time in practice that is important or the exposure to competency developing opportunities that matters? If it is exposure that matters (practice makes perfect model), then the arbitrary 10-week period may be unwarranted in students who are placed in placement sites with high case-mix exposure opportunities and/or active supervisory practices. This calls into question the assumptions underpinning this mandatory 10-week clinical placement requirement and suggests that minimum recommendations for placement OOS exposure may be a better guide than placement duration. This should be a focus for future research given the increasing pressure on the profession to take more students on clinical placements.

The cost and benefit analysis and comparison based on time use data in direct patient service delivery in the present study suggests that students need to be about $80 \%$ as time efficient in service provision as a new graduate across the whole 10-week placement period for the benefits of student service delivery to overcome the opportunity costs associated with direct supervision by practitioners. This finding needs to be considered with a clear recognition of the limitations of the student reported data collection method used in the present study. The validity of student records may be compromised for a number of reasons including recall errors, time estimation errors or even falsified data entries. Supervisor verification of data recorded for each OOS, however, is likely to have reduced this source of error. The post-placement debriefings explored these possibilities but did not identify any evidence from student feedback to suggest this was an issue.

Other studies have identified a range of intangible and difficult to quantify costs and benefits relating to clinical supervision. ${ }^{12,16}$ The present study focused cost and benefit analysis of student supervision based on quantification of observable time use by students and supervisors in direct patient care. Time is a measurable proxy measure that can be used to calculate costs and benefits. It is acknowledged that supervisors and managers spend time in 'invisible to student' supervisory work such as preparing cases, reviewing records and other tasks, before, during and after placements. This work is likely to be variable and the associated costs have not been calculated in the present study. Similarly, students perform productive work while on placement that has not been costed in the present study, including quality and research tasks.

More comprehensive data collection across the whole placement work profile is required to better estimate supervisory costs in future studies. A potential criticism of the assumption that student service provision should be counted as a contribution to department productivity and consequently counted as a benefit is that students are allocated cases that normally would not be seen by the practitioner/ supervisor. That is, the service is supernumerary and fabricated to meet student supervision objectives rather than service delivery objectives. We argue that a service, irrespective of the objective is a service, and it is in the interests of placement sites and practitioners to optimise the contribution to productivity that students can make by prioritising student case allocation to cases that need to be seen.

The assumptions used for estimating supervisory costs in our view are conservative and probably overestimate the costs of direct student supervision. This is based on our observation that many of the practitioners supervising students are on salary levels lower than that used to calculate costs. Future estimates should be based on individual supervisor costs rather than a blanket cost assumption. Despite these limitations, the simple economic analysis provides evidence that supports the earlier reported perception of supervisors that student placements do provide benefits that need to be weighed against the costs. ${ }^{7}$

The present study provides some of the first quantifiable data demonstrating the variability of student case exposure and supervisory practices in clinical dietetics placements. Estimates reflecting the effect of students on clinical dietetic department productivity suggest that the higher costs associated with more intensive supervision relative to student productivity in the early placement period need to be recouped in the later less supervised and more productive end of the student placement period. Clearly, more scholarship and debate relating to the role of clinical placements in competency development is warranted, in particular more detailed quantification of costs and benefits and investiga- 
tion of the type and quantity of competency developing exposures on placement process required to achieve entrylevel competency.

\section{Acknowledgements}

The contribution of the 59 Griffith University Master of Nutrition and Dietetics students in data collection is acknowledged. Melinda Spencer and Jane Desbrow contributed to data entry and Rowan Stewart provided editorial comment on early drafts of this paper.

\section{References}

1 Gilbride J, Conklin M. Benefits of training dietetics students in preprofessional practice programs: a comparison with dietetic internships. J Am Diet Assoc 1995; 96: 758-63.

2 Gilmore C, Maillet J, Mitchell B. Determining educational preparation based on job competencies of entry level practitioners. J Am Diet Assoc 1997; 97: 306-17.

3 Hughes R. Public health nutrition workforce composition, core functions, competencies and capacity: perspectives of advanced-level practitioners in Australia. Public Health Nutr 2003; 6: 607-13.

4 Hughes R. Competency development in public health nutrition: reflections of advanced level practitioners in Australia. Nutr Diet 2003; 60: 198-204.

5 Brown L, Capra S, Williams L. Profile of the Australian dietetic workforce: 1991-2005. Nutr Diet 2006; 63: 166-78.

6 Mitchell L, Capra S, MacDonald-Wicks L. Structural change in Medicare funding: impact on the dietetics workforce. Nutr Diet 2009; 66: 170-75.
7 Hughes R. Evaluation of university-initiated strategies for developing the supervisory capacity of professional placement sites for entry-level preparation in nutrition and dietetics. Nutr Diet 2002; 59: 191-4.

8 Roberts N, Brockington S, Doyle E et al. Innovative model for clinical education in dietetics. Nutr Diet 2009; 66: 33-8.

9 Roberts N, Brockington S, Doyle E et al. Pilot study of an innovative model for clinical education in dietetics. Nutr Diet 2009; 66: 39-46.

10 Kilminster S, Jolly B. Effective supervision in clinical practice settings: a literature review. Med Educ 2000; 34: 827-40.

11 Landmark B, Hansen G, Bjones I, Bohler A. Clinical supervision-factors defined by nurses as influential upon the development of competence and skills in supervision. J Clin Nurs 2003; 12: ••-•••.

12 Rodger S, Webb G, Devitt L, Gilbert J, Wrightson P, McMeeken J. Clinical education and practice placements in the allied health professions: an international perspective. J Allied Health 2008; 37: ••-••

13 Conklin M, Simko M. Direct economic benefits associated with dietetic internships. J Am Diet Assoc 1994; 94: 174-8.

14 Ovretveit J. Evaluating Health Interventions. Buckingham: Open University Press, 1998.

15 Mooney G. Economics, Medicine and Health Care, 2nd edn. Sydney: Harvester Wheatsheaf, 1992.

16 Hughes R. Evaluation of university-initiated strategies for developing the supervisory capacity of professional placement sites for entry-level preparation in nutrition and dietetics. Nutr Diet 2002; 59: 191-4. 


\begin{tabular}{|l|l|}
\hline \multicolumn{2}{|c|}{ Toppan Best-set Premedia Limited } \\
\hline Journal Code: NDI & Proofreader: Mony \\
\hline Article No: 1478 & Delivery date: 20 October 2010 \\
\hline Page Extent: 7 & Copyeditor: Ivan \\
\hline
\end{tabular}

\section{AUTHOR QUERY FORM}

\section{Dear Author}

During the preparation of your manuscript, the questions listed below have arisen. Please answer all the queries (marking any other corrections on the proof enclosed) and return this form with your proofs.

\begin{tabular}{|c|c|c|}
\hline Query no. & Query & Reply \\
\hline q1 & AUTHOR: Please confirm the corresponding information is correct. & \\
\hline$q^{2}$ & $\begin{array}{l}\text { AUTHOR: 'These data highlight the variability of student clinical placement . . . to } \\
\text { support student placements.' This sentence has been reworded for clarity. Please check } \\
\text { and confirm it is correct. }\end{array}$ & \\
\hline$q^{3}$ & $\begin{array}{l}\text { AUTHOR: The closing quotation mark has been added here; please confirm that this is } \\
\text { correct. }\end{array}$ & \\
\hline$q^{4}$ & AUTHOR: Please confirm the symbol '@' is correct here. & \\
\hline$q^{5}$ & $\begin{array}{l}\text { AUTHOR: 'Time is a measurable proxy measure that can be used to calculate costs and } \\
\text { benefits.' This sentence has been reworded for clarity. Please check and confirm it is } \\
\text { correct. }\end{array}$ & \\
\hline q6 & $\begin{array}{l}\text { AUTHOR: ' . . . is that students are allocated cases that normally would not be seen by } \\
\text { the practitioner/supervisor.' In this sentence, the word 'my' has been changed to 'by'; } \\
\text { please confirm that this is correct. }\end{array}$ & \\
\hline q7 & AUTHOR: Please supply the page range for Reference 11 . & \\
\hline q8 & AUTHOR: Please supply the page range for Reference 12 . & \\
\hline
\end{tabular}

